\title{
Migration and the Life Course in Contemporary Japan
}

\author{
Anthony J. FIELDING* and ISHIKAWA Yoshitaka** \\ *School of Social Sciences, University of Sussex, Brighton BN1 9QN, UK \\ **Department of Geography, Graduate School of Letters, \\ Kyoto University, Kyoto 606-8501, Japan
}

\begin{abstract}
This paper explores the relationship between migration and the life course in Japan. It does so by analysing a matrix of correlation coefficients where each coefficient measures the relationship between a set of age-specific net internal migration rates by prefecture (for example, for people aged 24-29), and a set of age structure location quotients by prefecture (for example, for people aged 60-64) (the location quotient measures the ratio of the local \% in a particular age-group to the national $\%$ for the same age-group). An extremely distinctive pattern of correlation emerges. This is analysed both on its own terms, and through a comparison with the equivalent pattern for Britain (England, Wales and Scotland). Surprising differences are discovered and interpreted.
\end{abstract}

Key words: migration, Japan, Britain, age structure, life course

\section{The Setting: Migration and the Life Course}

In a recent paper, some of the relationships and processes that link migration (both internal and international) with intra-generational social mobility in contemporary Japan were outlined (Fielding 1999). Most of that paper was about social class, gender and ethnicity, but a passing reference to the connections between migration and age, and in particular, to the way that internal migration patterns reflect the position of people in the 'life course' or 'life cycle,' was made. In this paper we investigate this relationship in more detail. Much of the paper is about Japan, but we also include a comparison of the migration/life course relationships between Japan and Britain.

It is well-known that internal migration rates show a high degree of age-selectivity. Much attention has been devoted to this aspect of migration over the years (Boyle, Halfacree and Robinson 1998, but see also Plane and Rogerson 1994), culminating in the international research project on 'migration and settlement' carried out since the mid-1970s (for example, Rogers and Castro 1981; Nanjo, Kawashima and Kuroda 1982; Rees 1979). A major finding from this kind of research was that countries that differ greatly in history, economy and culture nevertheless tend to share a very similar pattern of age-specific internal migration rates. Typically, the highest rates are for young adults in their early twenties with very high rates also for those in their late teens and late twenties. Migration rates then decrease through the thirties and forties to reach very low levels in the fifties. A small increase sometimes occurs around retirement age before the rates return to very low levels for those who are older. The rates for children tend to 'mirror' those of the parents with whom they migrate that is, high rates for young children, lower rates for older children.

As we shall show below, however, these similarities in national age-specific migration rates can hide important differences in the geographical direction of flow of age-specific migrants. Stated rather crudely, the demography might be the same, but the geography is very different!

Figure 1 shows the migration schedules for the Japan and the Britain (see below for comments on the comparability of the data). We can see that they are remarkably similar, but that the mobility of children is relatively low, and of young adults is relatively high in Britain, and that the mobility of those entering retirement age-groups and of the very elderly is rela- 


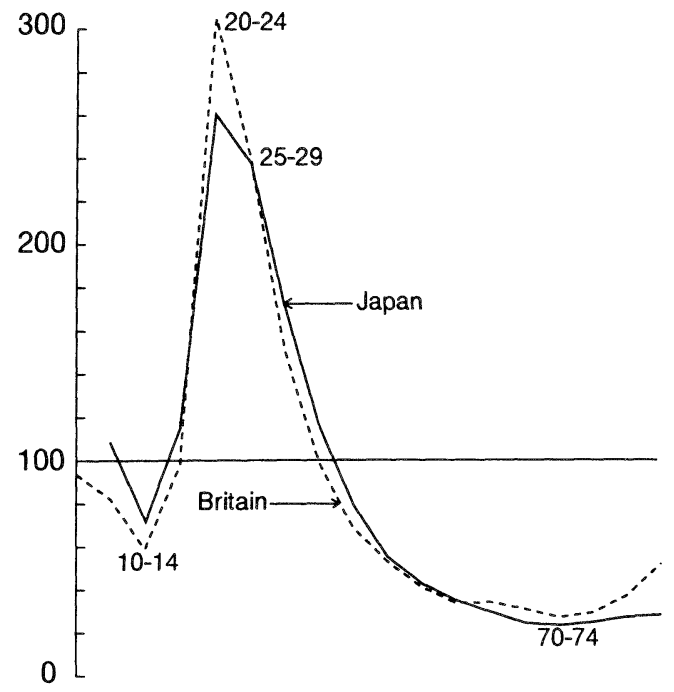

Figure 1. Age-specific migration rates, Japan and Britain.

National average $=100$

Sources: 1990 Census (Japan), 1991 Census (Britain)

tively high in Britain (for other useful studies of age-specific/life course migration in Japan see: Hashimoto and Murayama 1991; Hirai 1999; Hiroshima 1990; Inoue 1991; Ishikawa 2001a, 2001 b; Ito 1990; Kajita 1998; Kawabe 1984; Kawabe and Liaw 1994; Liaw and Otomo 1991; Morikawa 1992; Nakagawa 1990, 1996; Nishioka 2000; Oe 1995, 1996; Otomo 1981, 1994; Otomo, Liaw and Abe 1991; Ohzeki 1997; Sakai 1989; Shimizu 1984; Statistical Research Department 1990; Tabuchi 1998; Tahara and Iwadare 1999; Uchino 1987; Yamaguchi, Arai and Esaki 2000). However, despite the existence of numerous publications concerned with migration and the life course in Japan, there has been no detailed analysis of the age-specific migration/age structure relationship in Japan, or a comparison of this relationship between Japan and a western country.

To investigate this relationship between migration and the life course in more detail, we focus on age-specific net migration patterns across the 47 prefectures of Japan, and examine the associations between age-specific net migration rates and the age structures of places. The main research question that we attempt to answer is: 'does like attract like? - do places which have, for example, a high concentration of 20-24 year olds tend to attract migrants aged 20-24 ?'

Asking the question in this manner tends to indicate an expectation that the age characteristics of a place do in some way influence the attractiveness or unattractiveness of the place to particular age-groups in the population (i.e. age structure is cause, net migration is consequence). But migration is, of course, on both sides of the relationship, since the age structures themselves are in large part a consequence of the differential patterns of (past) agespecific migration - young adults leave certain places, thereby making them biased towards the elderly, and move to other places, thereby making them biased towards young adults (i.e. net migration is cause, age structure is consequence).

Following a short section on data and methods, the main part of the paper is in four parts: (i) first we explore the spatial distribution of Japan's population by five-year age-groups; (ii) then we do the same for age-specific net migration rates; (iii) the third section investigates the associations between the patterns described in (i) and (ii) above; and (iv) the fourth and final section compares the form that this relationship takes in Japan with that in the Britain. The style of the paper is descriptive and analytical rather than theoretical or interpretative, but the results have a more general significance because they warn us that the relationships that are common to the countries of Europe and North America may not apply to a third cluster of high-income countries - Northeast Asia.

\section{Data and Methods Used}

The data used in this paper are age-specific population figures, and age-specific migration figures taken from the Censuses of Japan and Britain. While the migration data for Japan are derived from the difference in place of usual residence between the census date at October 1st 1990 and five years before (October 1st 1985), the one for Britain is between the census date at April 21st 1991 and one year before (April 21st 1990). Thus the data used is for different periods. This is, without doubt, undesirable in an international comparison. Data 
based on the registration system, the other major data source for migration, are available in Japan, but they cannot, unfortunately, be disaggregated by age. Thus the use of the Census migration data is unavoidable.

However, the possible problems of such data for an international comparative study need to be noted here. A major cause of potential difficulty is the way that migrants who experience two or more moves during the five year period under consideration (1985-90) are counted. The annual report on internal migration based on registration data counts the number of actual migrations, but the censuses of Japan and Britain count only the number of migrants (people whose addresses differ between the census date and the date five (or one) year before). Even if a particular person moved five times during the inter-censal period, only one migration would be recorded. Especially worthy of note in this context is the case of the so-called 'U-turn' migration in Japan. This implies migration from an origin in a peripheral region to one of the three largest metropolitan areas centred on Tokyo, Osaka and Nagoya to get jobs or enter universities, and then a return to the origin within five years from the first migration. In this case the migrant may not be counted at all in the national census. Even though two or more changes of address in a five-year period is somewhat unusual, this problem of under-representation is nevertheless a weakness of the migration data derived from the Japanese census. One is unable to identify the extent of this problem because a nationwide comprehensive investigation of ' $U$-turn' migration has not been conducted. In other words, we cannot evaluate the seriousness of the problem of the different time intervals satisfactorily at this stage.

For an international comparison, we also need to keep in mind the economic conditions of that time (1985-90 for Japan and 1990-91 for Britain). The period covered by our study both in Japan and Britain coincided with a period of economic boom.

The spatial units used are the 47 prefectures of Japan and the 67 counties of Britain (comparable migration data is not available for Northern Ireland). The age classification used here has $17 \times 5$-year intervals $(5-9,10-14 \ldots 80-84$, $85+$ ). The age class $0-4$ is excluded due to a lack of residence for the whole or part of the population at the previous census (as yet unborn).

\section{Age Structures}

The first step in this process is to provide an efficient description of the Japanese population by five-year age group, by prefecture, for 1990 . The analysis is restricted to the population usually resident in Japan enumerated in the 1990 Census, but also resident in Japan in 1985 (this is to make it suitable as a base for the calculation of age-specific migration rates). It therefore excludes those who were born between 1985 and 1990 (as well as those who died between 1985 and 1990).

Before analysing the relationships between age-specific population and age-specific net migration, we look at each variable separately.

Each age structure map has been constructed in the following manner: (i) the percentage of the total population of Japan that is in a particular age group is the base figure, and is given as the low boundary of the lowest positive value on each of the maps (e.g. 6.39 for the age group 5-9); (ii) the standard deviation of the prefectural values is then used to define the class intervals, such that each class interval on the map is equal to one half of the standard deviation; (iii) positive values (i.e. those above the Japan figure) are then shaded with solid grey shading, negative values with proportional dots.

The main features of the age-structure maps, a small selection of which are shown in Figure 2, can be summarized as follows: First we can turn to children and young adults. Those aged 5-9 show high values in rural and peripheral regions, but low values in Tokyo and Osaka. This seems to closely reflect the spatial distribution of total fertility. Those aged 10-14 have a similar distribution but the high value for Shiga is noteworthy, and suggests that the relatively low cost of family housing there and recent economic development factors are at work. Those aged 15-19 show a sudden and remarkable switch. Now it is the centres of 


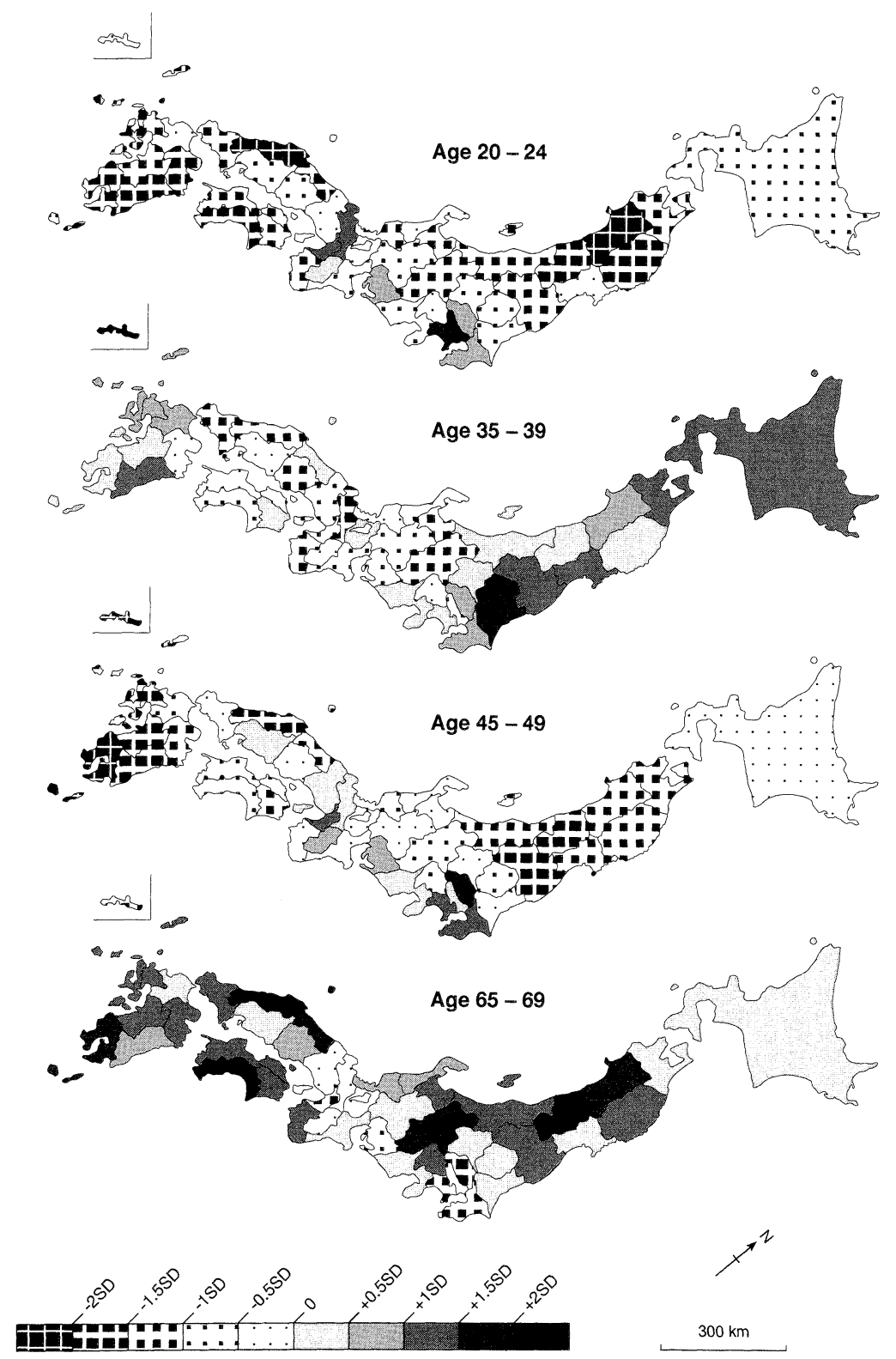

Figure 2. Age structure in 1990.

Age group as a \% of total population expressed in standard deviations from the mean by prefecture. Source: 1990 Census.

employment opportunity which have high values (eg southern Kanto, Nagoya/Aichi, and Kansai) and the periphery has low values. The middling value for Tokyo might perhaps be the result of counteracting processes - the inmigration of young workers and students on the one hand, matched by the out-migration of teenagers with suburbanizing or decentralizing parents on the other. Finally, the map for those aged $20-24$ is very distinctive. Now the student-young worker flow really kicks in, and the high values for Kyoto (student population) as well as those for Tokyo, Kanagawa and Osaka are very noticeable. At the same time there are very low values in the periphery, and hence this distribution has the highest standard deviation 
of all those in the series.

Secondly, we examine people of working age. In the case of those aged 25-29, the strong concentration in major metropolitan areas continues, with Tokyo especially prominent. Those aged 30-34 show a sudden shift. While elements of the previous pattern are still present (e.g.high value for Tokyo), high values are also found in some parts of the rural periphery. What might be the explanation for this? Undoubtedly there is some return migration (see below), but it is also likely that this was first group to be affected by the stop (or even slight reversal in some regions) of rural depopulation in the 1970-85 period (due to decentralization of employment, standardization of services and industrial restructuring). The effect of this is that these people are still living in the rural and peripheral areas rather than in the cities. The pattern for those aged 35-39 is almost the same, or rather even more so, since now there is no longer a high value for Tokyo. For those aged 40-44 another sudden shift occurs. The usual centre-periphery pattern reasserts itself (high values in main metropolitan regions), but it is accompanied by local decentralization in southern Kanto, involving people would have been entering the labour market in the late 60 s and early 70 s, i.e. at a period of rapid urbanization. This centre-periphery pattern is even clearer for people aged 45-49, and it is worthy of note that this pattern is very similar, apart from the local decentralization effect in southern Kanto, to that of the spatial pattern of income per capita (i.e. very high value in Tokyo, high values in the extended capital region, in Aichi and in the Kansai region, lower values in the prefectures containing the remaining regional capitals, and low or very low values elsewhere see Statistics Bureau, Japan Statistical Yearbook 2002, page 161). The map for those aged 50-54 shows a complex pattern, transitional between the group it follows and the one it precedes, and seems to largely reflect the different periods of major in-migration flows (for example, Osaka in the 1950 s resulting in a high value, and Shiga in the 1990s resulting in a low value). The pattern for those aged 55-59 then becomes much simpler. It has high values in the rural and peripheral regions, and low values in the main urban and metropolitan regions, and reflects the past out-migration of young adults during the period of rapid urbanization. This clear pattern is repeated for those aged 60-64, with rural areas and peripheral regions having many older inhabitants, and urban areas and metropolitan regions have few older inhabitants.

Finally, the map patterns of populations aged 65-69; 70-74; 75-79; 80-84; and 85+ are very similar to those aged $55-64$ (i.e. high values in rural areas and in the periphery), but it is noticeable that there is a trend for the high values to disappear in Hokkaido and Tohoku, but to remain in western Honshu.

\section{Net Migration}

The maps for age-specific net migration, a selection of which are shown in Figure 3, have been constructed in a very similar manner to those for age structures. The Japan total figure now becomes zero, since the number of outmigrants leaving prefectures must equal the number of in-migrants (remember we are dealing only with internal migration - all international migration flows are ignored). Once again the class interval is equal to one half of the standard deviation, and the map shadings reflect positive and negative values.

The main features of the age-specific net migration distributions are as follows: First, for children and young adults, those aged 5-9 show some regional elements (notably the net losses in Hokkaido and northern Honshu), but the main pattern element is the local decentralization effect, as main cities (Tokyo, Osaka and Kyoto) lose young families when they move to outer metropolitan areas (e.g. Saitama, Nara and Shiga respectively) in search of cheaper housing and (sometimes) better jobs. The map pattern for those aged 10-14 is very similar, but contains a stronger regional element. With those aged 15-19 we see a sudden and remarkable shift in pattern. Now it is the metropolitan areas which show strong net gains (notably Tokyo, Yokohama/Kanagawa, and Kyoto), while rural and peripheral areas show net losses. Also noticeable are the net gains to the regional cities (Nagoya, Fukuoka and Sendai - 


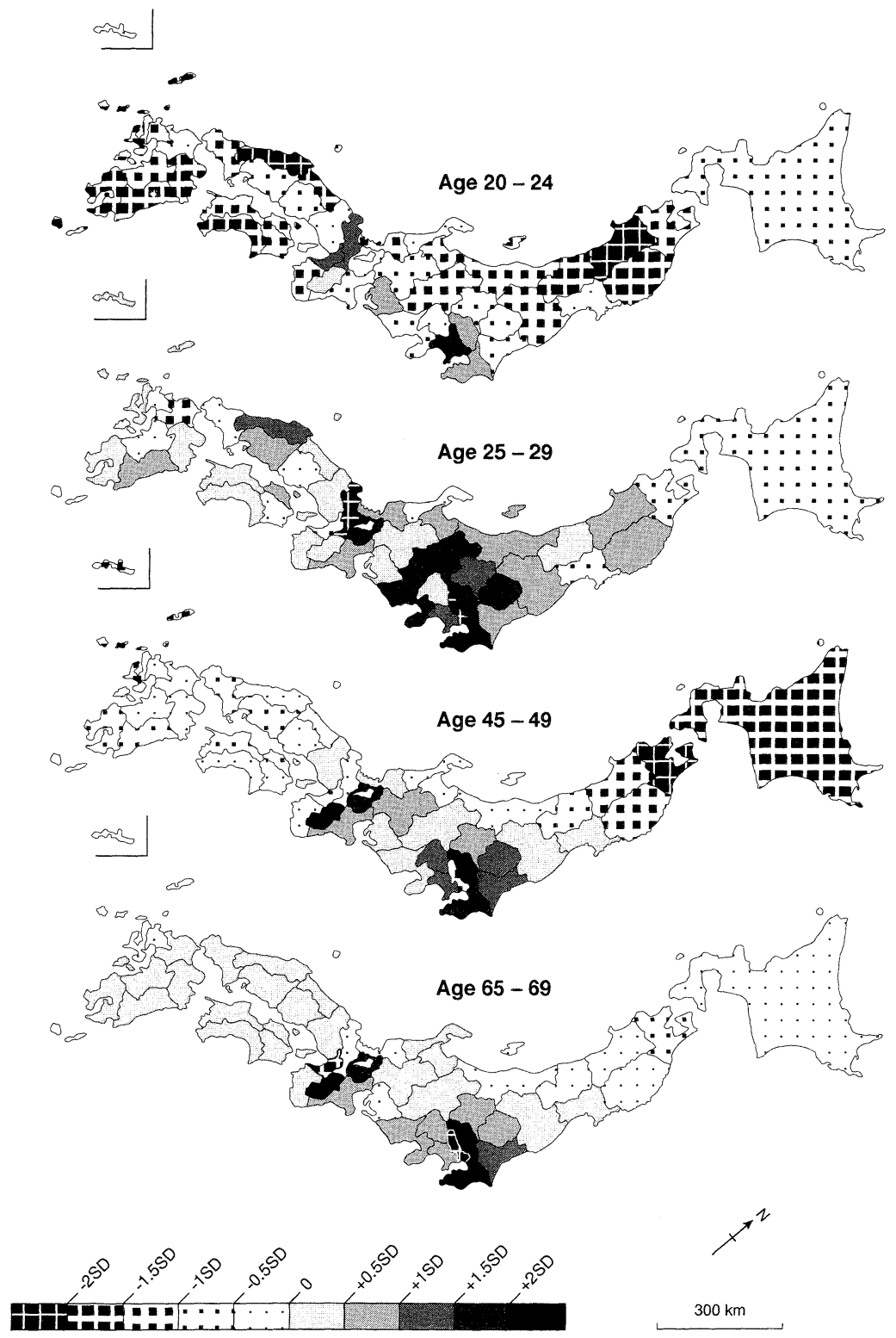

Figure 3. Net migration 1985-1990.

Net migration as a \% of total population expressed in standard deviations from the mean by prefecture. Source: 1990 Census.

all with large national universities). A similar pattern is found for those aged 20-24. What can be the explanation for this? We are witnessing the fact that young people are leaving rural and peripheral areas in large numbers for the jobs and higher education opportunities located in the main urban areas. It is not surprising, therefore, that this age-group is the one that has prefectural values with the highest standard deviation.

We turn, secondly, to those in the employment age-groups. With those aged 25-29 we see a sudden shift, but this shift is by no means a simple turnaround from the previous pattern. Tokyo and Kyoto (the main university cities) lose out to nearby and sometimes fairly distant regions; but it is noticeable that there is a contrast between the high rates of net gain around 
Tokyo and the much lower rates around Osaka/Kyoto (with the exception of Shiga). For those aged 30-34, two elements dominate (i) a broad regional pattern in which the periphery loses and central regions gain; and (ii) local decentralization. This distribution of net gains is understandable given (i) that this was a period of reconcentration of economic activity (especially on Tokyo) during the 'bubble economy' period; and (ii) because this high growth was heavily dependent on the expansion of the producer services sector (i.e. was metropolitan based). A very similar pattern emerges for those aged 35-39 with both broad regional and local components present. It is likewise for those aged 40-44, and although the map does not show this, the data tell us that the net gains of the region around Tokyo significantly outweigh the net losses of Tokyo itself, so the metropolitan region as a whole is still gaining. The map of net migration for those aged 45-49 is similar, but contains an even stronger regional concentration element. This is true also for those aged 50-54, with the distribution showing striking losses again in northern Tohoku and Hokkaido. The pattern for those aged 55-59 is similar, but contains a marked shift of regional gains towards the west and southwest. This trend towards gains in the west and southwest continues for those aged 60-64, and Osaka now joins Tokyo as an area of rapid net loss.

Finally, we turn to the net migration patterns of the older populations. Those aged 65-69 show a very similar pattern to those aged $60-$ 64 , except that the local effect is stronger relative to the regional element. For those aged 70$74 ; 75-79$; 80-84; and $85+$, local decentralization continues, but there is an increasing trend towards regional concentration with metropolitan regions gaining and rural and peripheral regions losing.

\section{The Association between Age Structure and Net Migration}

We can now begin to explore the relationship between these two variables - age structure and net migration. In a rather laborious fashion, this can be done visually by placing together a pair of maps, one of them for age structure and the other for net migration. If this were done for age structure 20-24 and net migration 20-24, for example, a striking similarity would be found. Such a similarity would not, however, be found when comparing the maps for those aged 65-69 with the net migration rates for those aged $65-69$. So the question becomes 'how can we best synthesise these correlations so as to depict the full range of similarities and differences?'

One answer is to plot the product moment correlation coefficients for all combinations of age structure patterns and net migration patterns in a single matrix and then see if there is any shape or pattern to the values that emerge. (There is no problem of ecological fallacy in this analysis since we are not inferring causality at the level of the individual on the basis of macro data. Nor are we concerned with the differential effects of the [demographic] characteristics of origins and of the [job] characteristics of destinations on migration flows.)

The correlation matrix is shown in Figure 4. Figure 4 has a number of extremely interesting and revealing features:

(i) the area to the right of age structure 50-54 is almost entirely composed of negative correlations, whereas the area to the left of this line is composed very largely of positive correlations. What this means is that migrants in Japan overwhelmingly prefer, or are constrained to migrate to, places which have younger populations in them over places which have older populations;

(ii) both the strongest positive correlations and the strongest negative correlations are reserved for the migrations of those aged between 15 and 24. The strong positive correlations are found in two concentrations: the first and largest is in those places which already have strong concentrations of such people we might expect that many of these migrants are students attending higher education institutions, and young people entering employment in large city locations. The second concentration is found where people in their forties live. As was pointed out above, this distribution closely matches the regional distribution of per capita income, so these young people are moving in line with economic opportunities. The 


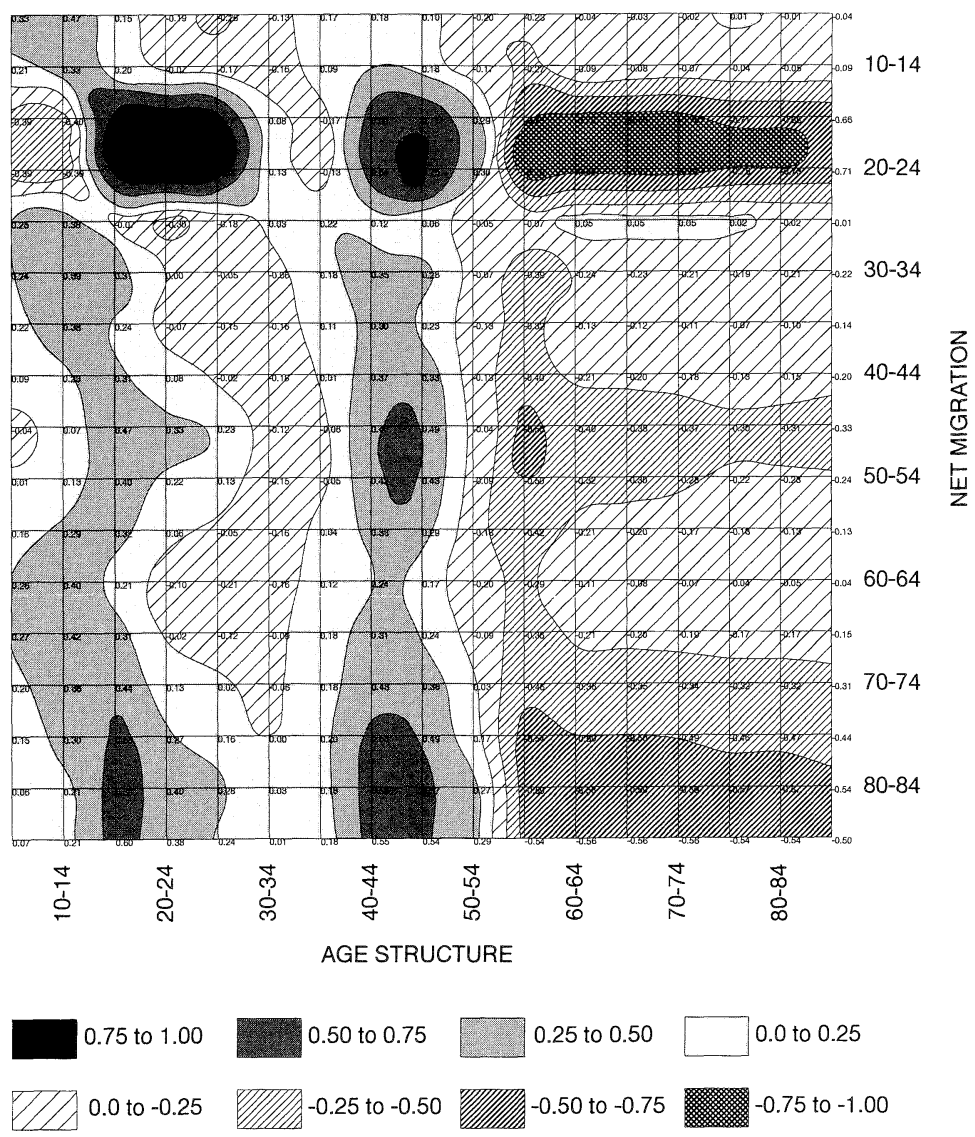

Figure 4. Japan: matrix of spatial correlations at prefectural level between age-specific net migration rates 1985-90 and location quotients for populations by age group 1990.

Source: 1990 Census.

very high negative correlations are for places which have high concentrations of elderly people living in them - this reflects the strong continuity into the recent period of the classic form of rural depopulation and of centripetal flows from the periphery to the core;

(iii) there is no evidence to support the expectation that high values would be found in the diagonal cells across the matrix. This expectation would be based on the notion that like would attract like,' that is, that for all age groups the net migration patterns would be biased towards their equivalent age-structure distributions. It has been shown, of course, that like attracts like in the case of the 15-24 year olds, but it turns out that this is the exception rather than the rule, and that in only one other case (the 45-49 year olds) does this positive correlation occur. An important implication of this is that Japan is, broadly speaking, a spatially immobile society, since were it to be very mobile, the correlation of net migration and age structure rates would perforce be closer (since the age structures would be less dependent for their formation upon past migration (plus in situ aging), and upon continuing fertility and mortality differences, and more dependent upon current age specific net migration rates);

(iv) rather than the diagonal line showing high positive values and the off-diagonal areas showing high negative values (as would occur under like attracting like), the one line of strong positive values is the vertical one coinciding with age groups $40-49$. Since this age distribution coincides with wealth and employment growth, the fact that all age groups correlate positively with it suggests that material gain still dominates (either directly or indirectly) 
Japanese internal migration behaviour. It would dominate directly for those in the labour market age groups, and indirectly those who are not in these age groups but whose dependence upon those who are, ensures that they share the same location pressures (i.e., the dependently young, and the dependently old);

(v) indeed the migration pattern correlations for the dependently old are very distinctive. Far from elderly people in their 70 s and 80 s tending to migrate to places where people of these ages are concentrated, they tend to gravitate towards those places where people in their forties and late teens live. This is surely reflecting elderly 'return' migration, 'return' that is, to the places where their children and grandchildren live (which is typically the outer areas of large metropolitan regions);

(vi) finally, one small but very peculiar feature of the correlation matrix cannot be overlooked. The migration patterns for the 25-29 age group are clearly very unusual or atypical. They are the opposite of those in the previous age group both with respect to age structure 20-24 and age structure 55-84. This is surely the manifestation of the migration effect of a remarkable concentration of higher education opportunities in the major cities, and especially in Tokyo and Kyoto. Once the students have graduated, a small but significant proportion do not stay on in the city or move to another city, but return 'home' to the areas characterised by elderly populations from which many of them came. That so few return is evidenced by the small scale of this feature compared to the massive feature of the previous migration to the city. It is, however, interesting to see how clearly this aberrant feature is picked up in the correlation matrix.

To conclude, this correlation matrix has revealed many interesting and important features of the Japanese internal migration system. We might be tempted to leave the matter there. But who is to say that these features are not common to all advanced capitalist societies? - perhaps Japanese migration flows simply reflect the common forces of an increasingly integrated global capitalist system. To check on this we need to compare these results with the association between age structures and net migration rates for another country for example, Britain.

\section{A Comparison of the Age-Structures/Net Migration Rates Correlation Matrices for Japan and Britain}

Figure 5 provides the equivalent correlation matrix for Britain. This was first produced using National Health Registration data by Yuzuru Isoda, a postgraduate geographer at the London School of Economics (and indeed it is due to his work on this topic that we became interested in this specific piece of research) (see Isoda 2001). It needs to be said that the datasets are not exactly the same - the British data is for counties (on average rather smaller in population than Japanese prefectures), and the migration data is for the year 1990-91 (i.e. at the end of the 5 -year period covered by the Japanese data). This use of one-year data allows the category $0-4$ as well as higher categories. In all other respects Figures 4 and 5 are identical in their constructions.

We can summarize the main differences and similarities between the two matrices as follows:

(i) whereas in Japan all age-specific net migration patterns favour the places where young people live over those dominated by the elderly, almost the opposite is the case in Britain. Why? What is going on here? Perhaps the key factors are to be found in a) the much higher degrees of socio-spatial segregation in Britain than in Japan, and b) in the related incentive in Britain for people to migrate in an effort to avoid places that have, or have the reputation of having, a higher risk of social conflict or of anti-social behaviour towards persons and property. Places in Britain where the elderly live tend to be safer places (rural areas, mixed rural/urban areas, small and mediumsized towns located in rural regions, and resort and coastal towns), i.e. places with higher life expectancy, lower morbidity rates, lower unemployment rates, lower crime rates, better housing, better public services etc. As such they are often preferred locations also for those bringing up children, for older people, and for those keen to achieve a balance between leisure-time ac- 


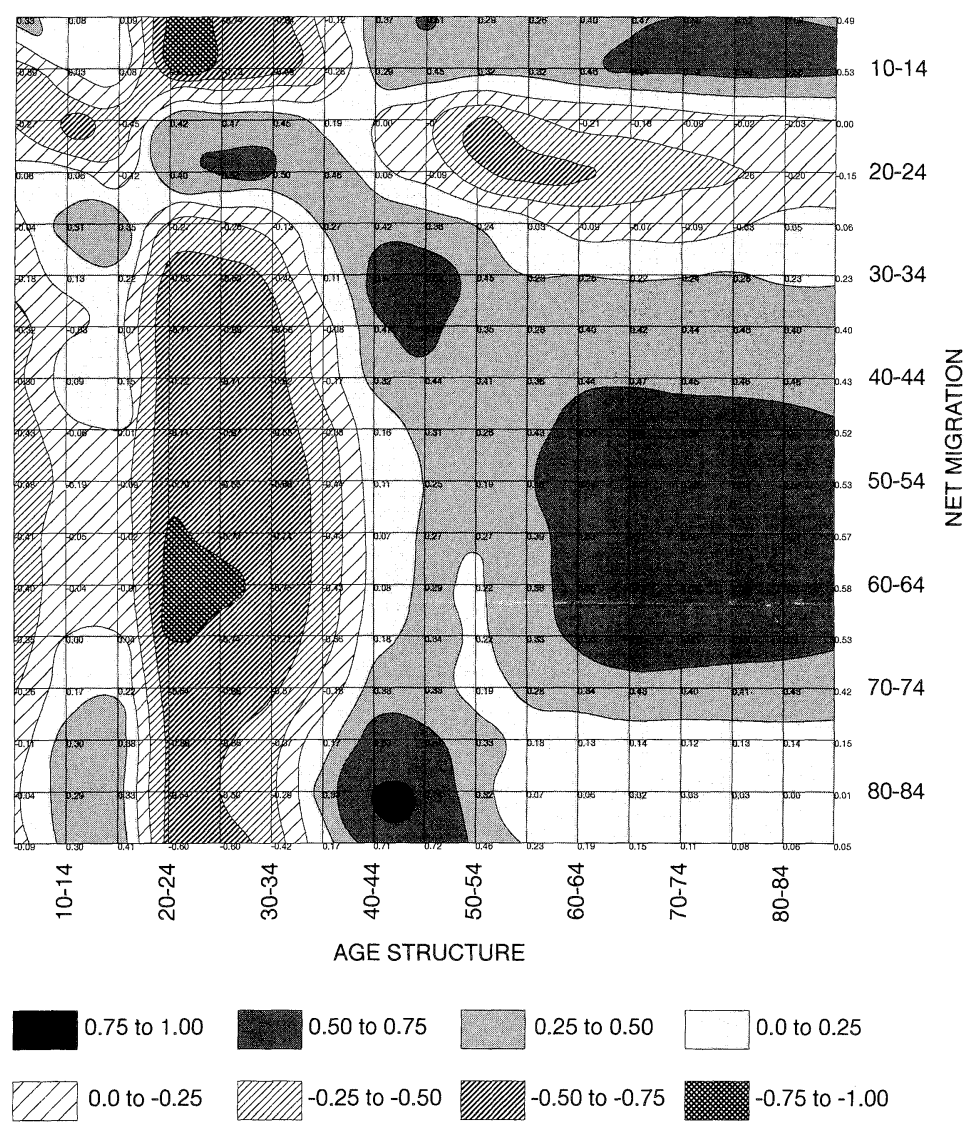

Figure 5. Britain: matrix of spatial correlations at county/region level between age-specific net migration rates 1990-91 and location quotients for populations by age group 1991 .

Source: 1991 Census.

tivities and work. It tends to be a minority notably the younger, early-career, unattached people - who prefer, or are constrained to migrate to, the large industrial or metropolitan cities (especially London);

(ii) the largest positive correlations in Britain are found to be those linking retirement-age migrants to places where retired people live. This represents an extraordinary difference between the two countries, and reflects the remarkably low level of retirement migration in Japan as well as the much higher level of individualistic (i.e. non-family-related) migrations of older people in Britain. The largest negative relationships in Britain are between the many middle-aged adult net migration age groups and the places where people in their twenties are concentrated;

(iii) in Britain there is a stronger tendency for diagonal values to be positive and for offdiagonal values to be negative than in Japan, indicating ceteris paribus a more spatially mobile society (i.e. the age structures tend more often than not to reflect the patterns of their equivalent net migration rates);

(iv) the dominant linear feature in the British case is the avoidance of the places where there are many people in their twenties (i.e. the counties/regions which are themselves, or are located in the centres of, large metropolitan regions). Significantly, this partially implies a negative association between net migration and income per capita, and perhaps therefore reflects the importance of lifestyle and social (e.g. 'white flight')-type factors over the material prospects factors that seem to dominate Japanese internal migration;

(v) one of the most interesting differences is 
for the dependent elderly. In Britain there is no net movement away from the places where the very elderly live, but, as with Japan, there are clear signs of 'return' elderly migration flows (i.e. return to the places where their offspring live), though in Britain this is mostly to places dominated by people in their forties and early fifties whereas in Japan it was also strongly towards teenagers (possibly grandchildren?);

(vi) the differences for child migrants is just as striking as those for the elderly. In Britain, the highest net migration gains are for those places dominated by the middle aged and elderly, while, in contrast, the places dominated by those in their late twenties and early thirties (that is, the metropolitan cities) are remarkable for their net migration losses of children. In Japan, no such strong patterns emerge;

(vii) finally, the correlations related to student and early adult work-related migrations are very different in the two countries. This partly reflects the fact that, unlike Tokyo, there is no massive concentration of university places in London and the South East, and no related return migration to rural areas and peripheral regions on graduation. Also, in the case of Britain, there is no positive correlation for net migration of those aged 25-29 with places where people aged 40-44 live (which is a major feature of the Japanese correlation matrix).

\section{Conclusions}

These detailed descriptions of the spatial patterns of the age composition of the Japanese population, and of the patterns of age-specific net internal migration, together with an analysis of the correlations between these distributions, have rather effectively revealed important features of the Japanese space-economy, and of the distinctive life-course features of Japan's internal migration. Among the most prominent general findings are: (i) that, while Japan and Britain are very similar with respect to their national age-specific migration rates, they are very different in the geographies of their interregional migrations; (ii) that economic factors seem to dominate Japanese internal migration patterns to a greater extent than those in Britain, where social factors seem to be more important; and (iii) that Japan seems to be a less geographically mobile society than Britain because its local age-structures reflect the age-structures of net migration less than do those in Britain. Thus this study has, in our opinion, provided us with (i) new insights into the relationships between net migration and the age-structure of places; (ii) new data on migration and the life course in Japan (and Britain); and (iii) as a result of this, some fascinating new perspectives on the nature of Japanese (and British) culture and society.

\section{Acknowledgments}

This research was conducted while Tony Fielding was Visiting Professor at the Department of Geography, Kyoto University. Yoshi Ishikawa is grateful for financial support from the Japanese Society for the Promotion of Science (Grant number 12308002).

(Submitted 6 May 2003)

(Accepted 10 July 2003)

\section{References}

Boyle, P., Halfacree, K., and Robinson, V. 1998. Exploring contemporary migration. Harlow: Addison Wesley, Longman.

Fielding, A. J. 1999. Migration and social mobility in contemporary Japan. Paper presented to the Annual Conference of the British Association for Japanese Studies, King Alfred's College, Winchester.

Hashimoto Y., and Murayama Y. 1991. Regional characteristics of the migration by sex and age classes in Aichi Prefecture. Touhoku Chiri 43: 122-138. (JE)

Hirai M. 1999. Characteristics of in-migration of the elderly in a suburb of Tokyo: A study of Tokorozawa City, Saitama Prefecture. Chirigaku Hyouron 72A: 289-309. (JE)

Hiroshima K. 1990. Parent-child residential relationship and migration from the viewpoint of children. Jinkou Mondai Kenkyuu 46: 16-34. (JE)

Inoue T. 1991. Regional difference of age-specific migration rates in Japan. Tsukuba Daigaku Jinbunchirigaku Kenkyuu 15: 223-250. (JE)

Ishikawa Y. 2001a. Kinki ni okeru nenrei kaikyuubetsu jinkou idou no henka. In Jinkou idou tenkan no kenkyuu, ed. Ishikawa Y., 115-136. Kyoto: Kyoto University Press. (J)

Ishikawa Y. $2001 \mathrm{~b}$. Jinkou idou sukejyuuru no henka kara mita jinkou idou tenkan. In Jinkou idou tenkan no kenkyuu, ed. Ishikawa Y., 207-256. Kyoto: Kyoto University Press. (J)

Isoda Y. 2001. British migration turnover. DSc thesis, 
Touhoku University.

Ito T. 1990. Household composition of migrants in Japan. Jinkou Mondai Kenkyuu 45: 30-45. (JE)

Kajita S. 1998. Migration and occupation careers of young male employees in a remote mountainous area: A case study of Wara village, Gifu Prefecture. Chirigaku Hyouron 71A(8): 573-587. (JE)

Kawabe H. 1984. Migration of metropolitan cores by age-group. Jinkou Mondai Kenkyuu 172: 63-66 (JE)

Kawabe H., and Liaw, K.-L. 1994. Selective effects of marriage migrations on the population distribution in a hierarchical region system in Japan. Geographical Review of Japan 67B(1): 1-14.

Liaw, K.-L., and Otomo A. 1991. Interprefectural migration patterns among young adults in Japan. Journal of Population Studies 14: 1-20.

Morikawa H. 1992. The 1985-90 net migration of age groups within Hyougo prefecture. Jinbum Chiri 44(4): 1-19. (JE)

Nakagawa S. 1990. Changing segregation patterns by age group in the Tokyo Metropolitan Area: From the viewpoint of migration with cohort analysis. Geographical Review of Japan 63B(1): 34-47.

Nakagawa S. 1996. Changing distribution of university graduates in Japan: From a cohort-by-cohort perspective. Jinkou Mondai Kenkyuu 52: 41-59. (JE)

Nanjo Z., Kawashima T., and Kuroda T. 1982. Migration and settlement: 13. Japan. RR-82-5, Laxenburg: International Institute for Applied Systems Analysis.

Nishioka H. 2000. Parent-child relationships in Japan: Determinants of parent-adult child co-residence. Jinkou Mondai Kenkyuu 56(3): 34-55. (JE)

Oe M. 1995. Cohort analysis of population distribution change in Japan: Processes of population concentration to the Tokyo region and its future. Jinkou Mondai Kenkyuu 51(3): 1-19. (JE)

Oe M. 1996. Cohort analysis of residential structure in Tokyo region. Sougou Toshi Kenkyuu 59: 21-34. (JE)

Ohzeki Y. 1997. The distribution pattern of urban migration in the Kanto region. Science Reports of the Institute of Geoscience, University of Tsukuba A 18: 1-36.

Otomo A. 1981. Mobility of elderly population in Japanese metropolitan areas. Journal of Population Studies 4: 23-28.
Otomo A. 1994. Elderly migration and population redistribution in Japan. In Elderly migration and population redistribution. ed. A. Rogers, 185-202. London: Belhaven Press.

Otomo A., Liaw, K.-L. and Abe T. 1991. Departure and destination choice processes in Japanese interprefectural migration: A characterization of overall and age-specific patterns. Geographical Review of Japan $64 \mathrm{~B}(1)$ : 1-23.

Plane, D. A., and Rogerson, P. A. 1994. The geographical analysis of population. New York: John Wiley.

Rees, P. H. 1979. Migration and settlement: 1. United Kingdom. RR-79-3, Laxenburg: International Institute for Applied Systems Analysis.

Rogers, A., and Castro, L. J. 1981. Model migration schedules. RR-81-30, Laxenburg: International Institute for Applied Systems Analysis.

Sakai H. 1989. The elderly migration: Characteristics and reasons. Jinkou Mondai Kenkyuu 45(3): 1-13. $(\mathrm{JE})$

Shimizu H. 1984. Introduction to the study of 'family reasons' in geographical mobility. Jinkou Mondai Kenkyuu 169: 17-30. (JE)

Statistical Research Department. 1990. Migration rates by age group and migration patterns: Application of Rogers's migration schedule model to Japan, the Republic of Korea and Thailand. Tokyo: Institute of Developing Economies, Statistical Data Series 54.

Statistics Bureau ed. 2001. Japan statistical yearbook 2002. Tokyo: Japan Statistical Association.

Tabuchi R. 1998. Determinants of parent-child coresidence: The case of Japanese elderly women. Jinkou Mondai Kenkyuu 54(3): 3-19. (JE)

Tahara Y., and Iwadare M. 1999. Where the elderly move to: A review and a study of elderly migration flows in Japan. Toukyou Daigaku Jinbun Chirigaku Kenkyuu 13: 1-53. (JE)

Uchino S. 1987. Elderly migration in Japan: Newly emerging trend and its analysis. Jinkou Mondai Kenkyuu 184: 40-57. (JE)

Yamaguchi Y., Arai Y., and Esaki Y. 2000. Migration trends of young jobseekers in and around peripheral regions in Japan. Keizai Chirigaku Nenpou 46 (1): 43-54. (JE)

$(\mathrm{J})$ : written in Japanese

(JE): written in Japanese with English abstract 